\title{
The quantitative analysis of neurodegenerative disease: classification, noda, constellations, and multivariate geometry
}

\author{
Richard A. Armstrong \\ Vision Sciences, Aston University, Birmingham, United Kingdom
}

Folia Neuropathol 2018; 56 (1): 1-13
DOI: https://doi.org/10.5114/fn.2018.74654

\begin{abstract}
A variety of methods are available for the quantitative description and analysis of neurodegenerative disease. If neurodegenerative disease exists as a series of distinct disorders, then classificatory methods such as hierarchical cluster analysis (HCA) and decision tree analysis (DTA) can be used to classify cases into groups more objectively. If neurodegenerative disease consists of overlapping phenotypes, then the Braun-Blanquet 'nodal' system and 'constellation diagrams' implicitly recognise intermediate cases and reveal their relationships to the main groupings. By contrast, if cases are more continuously distributed without easily distinguishable disease entities, then methods based on spatial geometry, such as a triangular system or principal components analysis (PCA), may be more appropriate as they display cases spatially according to their similarities and differences. This review compares the different methods and concludes that as a result of the heterogeneity and overlap commonly present plus the multiplicity of possible descriptive variables, methods such as PCA are likely to be particularly useful in the quantitative analysis of neurodegenerative disease. A more general application of such methods, however, has implications for studies of disease risk factors and pathogenesis and in clinical trials.
\end{abstract}

Key words: neurodegenerative disease, distinct disorder, overlapping phenotypes, continuum, multiple pathology, classification, principal components analysis (PCA).

\section{Introduction}

Three hypotheses have been proposed to describe neurodegenerative disease as a whole [8]. First, as a result of the complex interactions between correlated groups of clinical and pathological features, distinguishable disease entities exist which can be described, named, and classified. This hypothesis represents an essentially traditional view of neurodegenerative disease as comprising a series of more or less distinct 'named' disorders such as Alzheimer's disease (AD) [3], dementia with Lewy bodies (DLB) [52],
Pick's disease (PiD) [62], and Creutzfeldt-Jakob disease (CJD) [27,45]. Second, although distinctive neurodegenerative disorders may exist, cases are frequent which exhibit more than one type of pathological change, variously described as 'intermediate cases', 'overlap cases', or as examples of 'multiple pathology' $[14,46]$. Hence, cases have been described which combine the features of $A D$ and vascular dementia (VD) [33,61,69,70], AD and DLB [5,11,29, $30,36,43,53,57]$, or AD and CJD [40]. More complex combinations of cases with three or more 'multiple pathologies' are also being described and are

\section{Communicating author}

Dr Phil. Richard A. Armstrong, Vision Sciences, Aston University, Birmingham B4 7ET, United Kingdom, phone: 0121-204-4102, fax: 0121-204-4048, e-mail: R.A.Armstrong@aston.ac.uk 
increasingly difficult to accommodate within conventional classificatory systems $[14,18,46,48,77]$. Third, no two individual cases of neurodegenerative disease are identical and cases as a whole exhibit more or less continuous variation in clinical and pathological features and therefore, form a 'continuum' within which definable entities cannot be easily distinguished [8].

Which of these three hypotheses will ultimately prove to be the most realistic description of neurodegenerative disease remains to be established [8]. Nevertheless, there has been a growing awareness that the traditional division of neurodegenerative disease into distinct entities may not be fully justified and that phenotypic variation, overlap, and the presence of multiple pathology are characteristic of many disorders $[8,14,46]$. As a result, there have been calls for a reconsideration of existing disorders and for a new 'classification' of neurodegenerative disease which can take these factors fully into account $[8,14,31,35,58,60]$.

A variety of methods are available for the quantitative analysis of neurodegenerative disease, many being associated with the analysis of data from MRI, FDG-PET, or genome scans of dementia patients, and concerned essentially with classification and diagnosis $[2,49,67]$. The utility of a quantitative method, however, will depend on which of the three hypotheses best describes neurodegenerative disease. If distinct disorders exist, then classificatory methods such as hierarchical cluster analysis (HCA) or decision tree analysis (DTA) could be used to classify cases into groups more objectively. However, if neurodegenerative disease consists of relatively distinct disorders but with frequent intermediate cases [14], methods such as the 'Braun-Blanquet nodal' system [20] or 'constellation diagrams' [1] could be used which implicitly recognise intermediate cases and reveal their relationships to the main groupings. If cases are continuously distributed without easily distinguishable disease entities, then methods based on spatial geometry may be more appropriate [63]. Such methods arrange cases of disease with reference to a co-ordinate frame such that their similarities and differences are spatially represented $[12,17,63]$. The objective of this review is to illustrate the application of these methods and to identify those which may prove to be the most useful in the analysis and description of neurodegenerative disease.

\section{Methods based on classification}

The theoretical basis for classifying neurodegenerative disease is that clinico-pathological groups of cases exist which are distinct enough to be 'named' as a disorder, such that within a group, cases are more or less homogenous and intermediates between one group and another relatively rare. The continued recognition of many familiar 'historical' disorders such as AD [3], DLB [52], PiD [62], and CJD [27,45] is largely based on this assumption. If distinct groupings of cases exist, it would be logical to use quantitative methods to attempt to classify cases into these groups more objectively. A variety of such methods exist and this review describes two basic types: (1) HCA [63], and (2) DTA [64]. More complex methods include 'orthogonal projection to latent structures' (O-PLS), a method which can be used in circumstances if there are more descriptive variables than cases [74], 'support vector machines' (SVM) in which given an existing binary classification, an algorithm assigns new examples to the existing classification [25], and 'artificial neural networks' (ANN) which are based on biological neural networks and which essentially 'learn', i.e., progressively improve their performance over time [66].

\section{Hierarchical cluster analysis}

Hierarchical cluster analysis (HCA) results in a classification of cases based on a measure of their similarity, cases being joined or linked into groups successively to form a tree or dendrogram $[10,37,72]$. Many such methods have been described [63] but relatively few have been applied to the classification of neurodegenerative disease as a whole. HCA has been used to classify cases of primary progressive aphasia (PPA) [76] and behavioural variant fronto-temporal dementia (bvFTD) [78] and has also been used to detect common features among different neurodegenerative diseases such as AD, CJD, and fatal familial insomnia (FFI) [73].

The first problem to be considered using HCA, which assumes normally distributed data, is whether the defining variables include qualitative (presence/ absence) data, semi-quantitative scores, continuous quantitative measures such as density or 'load', or a mixture of all three [6]. In addition, variables may have been measured on different scales with substantially different means and standard deviations (SD) and variables with especially high means and 
SDs could bias the results of the analysis. As a consequence, the data can be 'standardised' by converting all variables so that they are members of the same distribution, most commonly the standard normal distribution. Second, distance ' $d$ ' is required which measures the similarity of one case to another. There are various methods of calculating ' $d$ ' but the simplest is to assume that the ' $\mathrm{S}$ ' descriptive variables are dimensions making up an S-dimensional space, 'Euclidean distance' being used as a similarity measure by the application of Pythagoras' theorem. Third, a linkage rule needs to be chosen to determine how similar cases are joined together to form larger groupings, the 'un-weighted pair-group method using arithmetic averages' (UPGMA), in which all distances contribute equally to each average, being commonly used [24].

An example of an HCA applied to cases of frontotemporal lobar degeneration (FTLD) with transactive response (TAR) DNA-binding protein 43 (TDP-43) proteinopathy (FTLD-TDP) is shown in Figure 1. Studies suggest that FTLD-TDP is neuropathologically heterogeneous [17] with division into four subtypes (currently designated A, B, C, and D) based on the distribution and density of 'signature' pathological inclusions in the cortex $[22,47,55,68]$. Division of FTLD-TDP into subtypes is often made subjectively and HCA could be used to establish their validity. Hence, neuropathological variation among 94 cases of FTLD-TDP, previously assigned subjectively to subtypes $A$ to $D$, was studied using quantitative estimates of the density of the TDP-43-immunoreactive neuronal cytoplasmic inclusions $(\mathrm{NCl})$, neuronal intranuclear inclusions (NII), dystrophic neurites (DN), and oligodendroglial inclusions (GI) in frontal and temporal lobes [17]. To establish the groups, the 'amalgamation schedule' is examined, i.e., the linear sequence in which cases were joined, and a 'decision line' (DL) defined where there is a steep rise in the curve, i.e., the point at which more distinctive groups are being joined together.

The analysis resulted in four main groups of cases (1-4), the remaining forming a residual or miscellaneous group $(M)$ not closely related either to each other or to groups 1-4. Group 1 is a small group defined by particularly high densities of DN throughout the frontal and temporal lobe with the exception of the DG, and with a preponderance of sporadic cases, the majority representing subtype C. Group 2 is a group of mainly sporadic cases

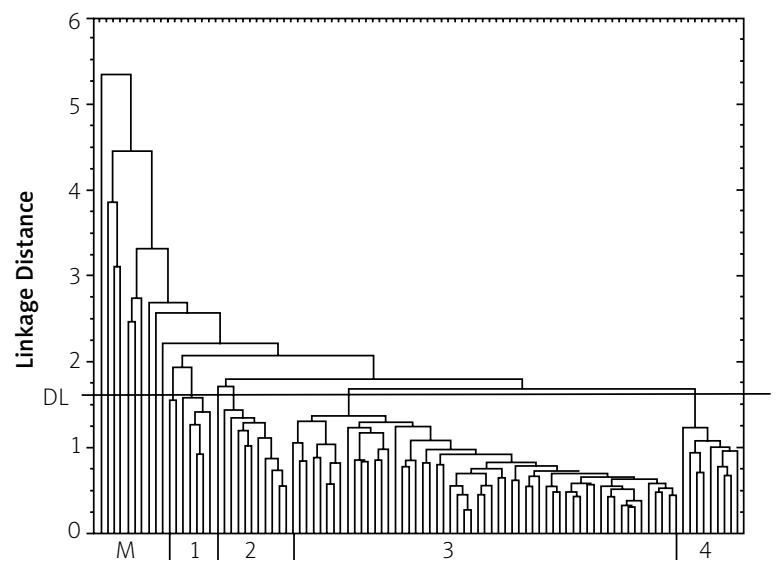

Fig. 1. An example of an objective 'classification' using hierarchical cluster analysis (HCA) of 94 cases of frontotemporal lobar degeneration with TDP proteinopathy (FTLD-TDP) resulting in a dendrogram. The dendrogram was obtained using the hierarchic clustering 'un-weighted pair-group method using arithmetic averages' (UPGMA) and 'Euclidean distance' as a measure of the 'similarity' between cases, $\mathrm{DL}$ - decision line used to establish the groups, 1-4 resultant groups of cases; $M$ - miscellaneous group of cases.

defined by a high density of $\mathrm{NCl}$ in the DG with DN in some regions, various subtypes being represented. The majority of cases within group 3, the largest group, were defined by relatively low densities of TDP-43-immunoreactive inclusions, continuous variation among cases, and comprised various subtypes. The dendrogram suggests that this group could be further subdivided by establishing a DL at a lower linkage distance. Group 4 is predominantly sporadic and defined by $\mathrm{NCl}$ in the upper cortex and in the DG and comprises mainly subtype B. Group $M$ is the most heterogeneous, the cases being predominantly familial and characterised by high densities of $\mathrm{NCl}$ and $\mathrm{NII}$ together with moderate densities of DN. Hence, the more 'objective' classificatory method confirms the considerable heterogeneity within FTLD-TDP but does not fully support the subjective division of cases into distinct subtypes [17].

\section{Decision tree analysis}

In contrast to HCA, decision tree analysis (DTA) is used to predict group membership of cases $(Y)$ from 
measurement of one or more predictor variables $(X)$ and is an important method of 'data mining' [64]. DTA is closely related to both discriminant analysis and to HCA but regarded as more flexible than either [64]. DTA can be calculated using categorical predictor variables, continuous predictor variables, or a mixture of both, the method assuming that predictors are measured at least on an ordinal scale and therefore DTA is less stringent in its assumptions of normality than other types of the classificatory method. DTA has been used to classify AD cases according to the expression of different pathogenic genes $[39,49,79]$. In addition, FDG-PET scans of human patients often include DTA among their automatic classificatory techniques [69].

'Classification and regression tree' (C\&RT) is one of the most commonly used DTA methods [21] and an example applied to the classification of a group of $A D$ and control cases based on the density of neurofibrillary tangles (NFT) in three brain regions, viz., superior frontal gyrus (SFG), parahippocampal gyrus (PHG), and sector CA1 of the hippocampus is shown in Figure 2. First, box 1 is the 'root node' in which all

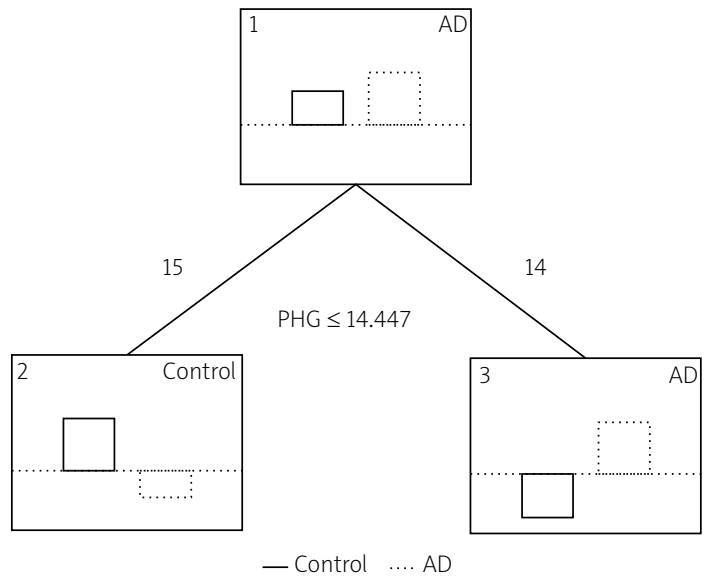

Fig. 2. Decision tree analysis (DTA) of 13 control and 16 Alzheimer's disease (AD) cases based on the density of neurofibrillary tangles (NFT) in the superior frontal gyrus (SFG), parahippocampal gyrus (PHG), and sector CA1 of the hippocampus and carried out by the 'classification and regression tree' (C\&ART) method ( 1 - 'root node', 2, 3 - 'child nodes'). Histograms show how many cases of each type are 'classified' within each child node. The split is made on the basis of density of NFT within the PHG, a density $>14.48 \mathrm{NFT} \mathrm{mm}^{-2}$ defining AD. control and $A D$ cases are shown by the relevant histograms. Second, boxes 2 and 3 are the 'child nodes' resulting from classifying the original total number of cases into two groups. Third, boxes 2 and 3 also show how the AD and control cases have been allocated. Hence, box 2 contains 15 of the original cases, 12/13 control cases and 3 'misclassified' AD cases while box 3 contains 14 of the original cases, 13 AD cases and 1 misclassified control. Fourth, the analysis selects the density of NFT in the PHG as the basis of the split, densities greater than 14.45 NFT $\mathrm{mm}^{-2}$ being necessary to discriminate $A D$ from controls. Hence, a reasonable classification was achieved but with three misclassified AD cases and one control, reflecting the complexity of the interface between $A D$ and the cognitively normal elderly [7], the basis for the separation among the groups also being identified. By contrast, the 'chi-square automatic interaction detection' (CHAID) method of DTA has been used to classify $A D$ cases based on various cerebral spinal fluid (CSF) markers as variables $\left(\mathrm{Ab}_{1-42}\right.$, total tau, phosphorylated tau (p-tau) [19]. The first step decision was based on $A b_{1-42} / p$-tau ratio and the second step on p-tau alone.

\section{Methods accommodating overlapping phenotypes}

If neurodegenerative disease consists of relatively distinct disorders but with a degree of overlap among the different entities [14], cases exhibiting intermediate features or multiple pathology are likely to be common [46]. Hence, a descriptive system is required which can recognise both the major groupings but also accommodate the overlap cases. Two such methods are described: (1) a semi-objective method based on 'Braun-Blanquet nodal' system, originally used to classify vegetation in the natural world [20] and (2) 'constellation' diagrams using a system based on either chi-square $\left(\chi^{2}\right)$ [1] or Pearson's correlation coefficient (' $r$ ') [28]. Neither of these methods have been previously applied to neurodegenerative disease.

\section{Braun-Blanquet's 'noda'}

The basis of Braun-Blanquet's system [20] is the 'nodum', a concept which in the context of neurodegenerative disease corresponds to a basic disease entity, and is an abstraction obtained from lists of clinical and pathological features obtained from 
a series of randomly selected cases. An example of this approach applied to 12 cases, six each of two closely-related disorders, viz. corticobasal degeneration (CBD) [13] and progressive supranuclear palsy (PSP) $[15,54]$ and based on six defining pathological features is shown in Figure 3. From a two-way table of cases and the presence/absence of defining features, it is possible to establish those characteristics which occur in a given number of cases and therefore, to establish 'constant' features. In this example, only astrocytic plaques (AP) and tuft-shaped astrocytes (TSA) appear to differentiate the two groups of cases. Cases which have AP are grouped together initially to form nodum $X$ (representing CBD) while cases which have TSA are designated as nodum $Y$ (representing PSP). However, there are also cases which share the features of $X$ and $Y$ and have both AP and TSA (cases E, F, G), and these are identified as the intermediate or overlap cases. Hence, the concept of noda may be useful in neurodegenerative disease because it implies not only the existence of valid groupings, but also intermediate cases. The Braun-Blanquet system, however, relies on the assumption that relatively distinguishable disease entities actually exist [8]. In addition, there is a degree of subjectivity in establishing the position of the noda. Nevertheless, if neurodegenerative disease is ultimately shown to be distributed in relatively distinct groups but with less common intermediate cases, then the Braun-Blanquet system could provide a useful description of the noda and the regions of overlap.

\section{Constellation diagrams}

Constellation diagrams provide a two-dimensional representation of a sample of cases using either $\chi^{2}$ as a measure of the association between all pairs of cases if the data are qualitative [1] or Pearson's correlation coefficient ' $r$ ' if data are quantitative [28]. The degree of similarity is displayed as a 'constellation' diagram using the reciprocal of $\chi^{2}$ or ' $r$ ' as a measure of distance between each pair of cases. An example of this method applied to 12 cases of $A D$ and DLB and based on the presence/ absence of Lewy bodies (LB) and AD pathology in the form of $\beta$-amyloid $(A \beta)$ deposits in regions of the frontal and temporal lobe is shown in Figure 4. Four of the cases, identified originally as 'pure' DLB (bottom right), form a cluster of closely linked cases

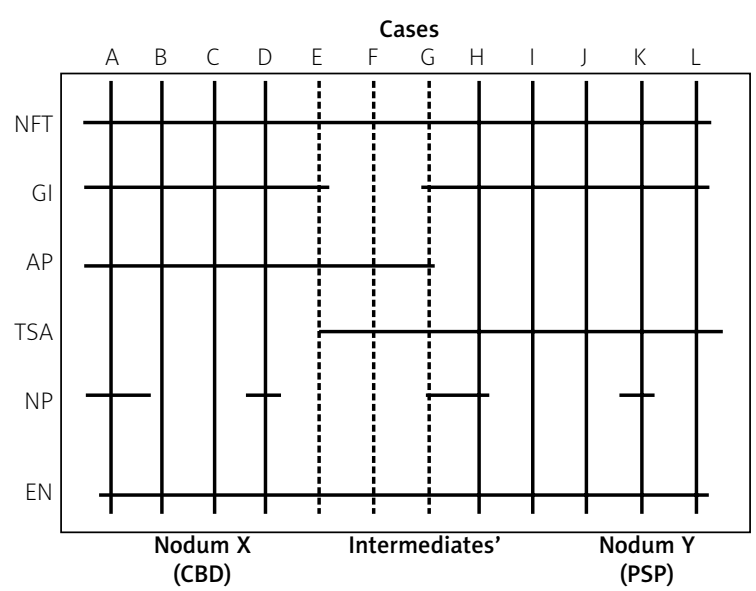

Fig. 3. Braun-Blanquet's 'nodal' method: Letters A to $L$ represent cases of corticobasal degeneration (CBD) and progressive supranuclear palsy (PSP) defined by various pathological features (NFT - neurofibrillary tangles, GI - oligodendroglial inclusions, AP - astrocytic plaques, TSA - tuft-shaped astrocytes, NP - neuritic plaques, EN - abnormally enlarged neurons). The presence of neuropathological features is indicated by vertical lines while cases with the same features are joined horizontally. Cases which have the same constant feature, e.g., astrocytic plaques (AP) are grouped together to form nodum $X$ (representing CBD) while cases which have a different constant feature, i.e., tuft-shaped astrocytes (TSA) are designated as nodum $Y$ (representing PSP). There are also cases which share the constant features of both $X$ and $Y$ (cases E, F, G) and these are the intermediate or overlap cases.

$(p<0.01)$ with a degree of spatial separation from those cases which also have $A D$ as a co-pathology (DLB/AD) and with a clear separation from two 'pure' $A D$ cases, a closer spatial relationship being present with two further AD cases [44]. Such a spatial separation is obtained using the large positive associations between cases, the general positioning of the clusters then being determined by the negative associations. It is unlikely in this type of analysis that any of the resultant groupings will be completely isolated from the others, each will be linked to adjacent groups by associations between its members via the intermediate cases. In addition, the strength of the linkages can be assessed by the associated 'P' values, in this case the stronger connections indicated 


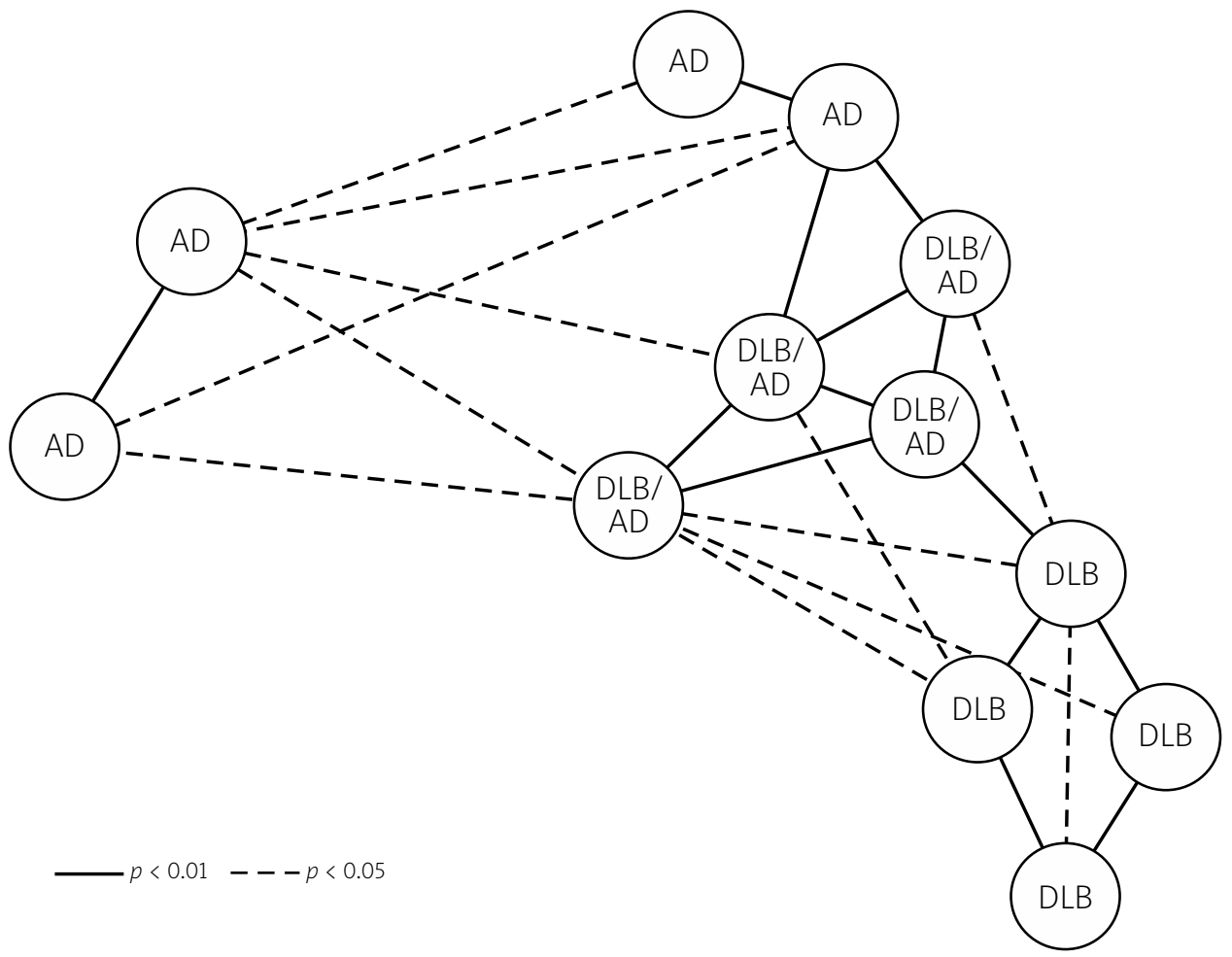

Fig. 4. A chi-square $\left(\chi^{2}\right)$ constellation diagram illustrating the spatial relationships between a group of dementia with Lewy bodies (DLB) cases with and without associated Alzheimer's disease (AD) pathology and 'pure' AD. Linkages are shown statistically significant at the $p<0.01$ and $p<0.05$ level. Four of 'pure' DLB (bottom right) form a cluster of closely linked cases $(p<0.01)$ with some degree of spatial separation from those cases which also have $A D$ as a co-pathology (DLB/AD) and with a clear separation from two of the 'pure' AD.

by $p<0.01$ and the weaker by $p<0.05$. Hence, as in the Braun-Blanquet system, the method enables clusters of cases comprising the major groupings to be identified ( $A D$ and $D L B$ ) but also indicates which cases could be intermediates (AD/DLB) and illustrates the affinities of the more complex cases with the main groupings. The disadvantage of such a system is its two dimensional representation and therefore, a degree of subjectivity in determining the relative location of the cases.

\section{Methods based on spatial geometry}

Neurodegenerative disease may be too heterogeneous and the degree of multiple pathology too frequent for any of the previous methods to provide an adequate description of the distribution of cases. Hence, cases of neurodegenerative disease may represent a 'continuum' of the phenotypic change rath- er than being distributed in distinct groups [8,14,17]. The often complex relationships that exist among cases suggest that dimensions of phenotypic variation are present which are too complex to be represented by dendrograms, decision trees, noda, or constellation diagrams. Hence, there may be a requirement to display these relationships more realistically using multivariate geometry in which the similarities and differences among cases are spatially represented [63]. This review describes two such methods: (1) a triangular system based on three descriptive axes and (2) principal components analysis (PCA) which uses a more complex multivariate approach.

\section{A triangular system}

If neurodegenerative disease can be described by three major neuropathological variables, then a triangular system could be used to display the cases 


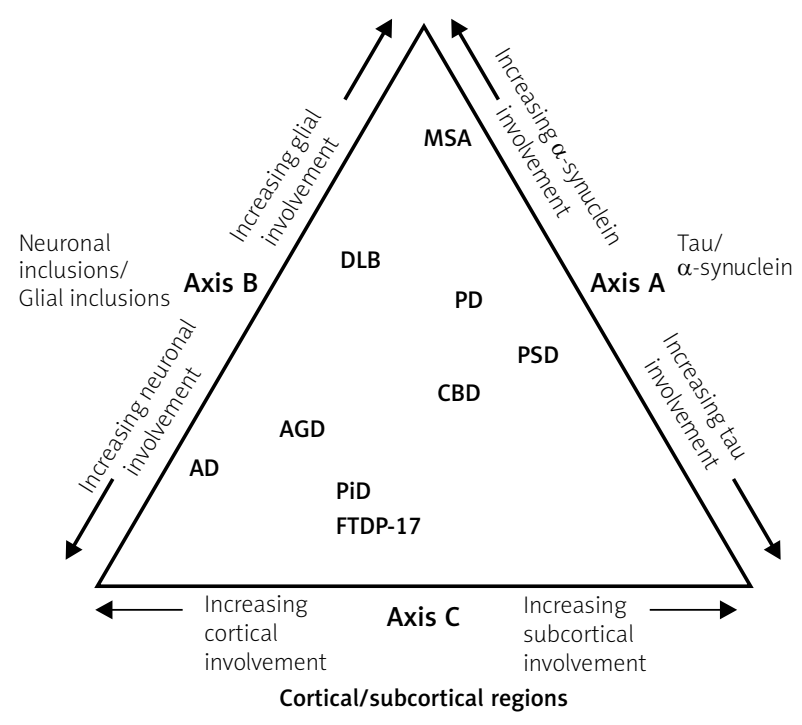

Fig. 5. A triangular system to plot neurodegenerative disease according to three major variables (axes A, B, and C). The approximate locations of 'classic' cases of various tauopathies and synucleinopathies within the space are indicated $(A D$ - Alzheimer's disease, AGD - argyrophilic grain disease, CBD - corticobasal degeneration, DLB - dementia with Lewy bodies, FTDP-17 - frontotemporal dementia and parkinsonism linked to chromosome 17, MSA - multiple system atrophy, PiD - Pick's disease, PD - Parkinson's disease, PSP - progressive supranuclear palsy).

[38]. As an example, a triangular system is used to describe cases representing two major molecular groupings, viz., the tauopathies and synucleinopathies, cases which often exhibit considerable heterogeneity and overlap $[14,32,56]$. The three variables used to describe each case are represented by the three sides of an equilateral triangle $(A, B, C)$ (Fig. 5): (1) the ratio of the densities of the pathology in cortical to subcortical regions (axis A), (2) the ratio of densities of neuronal to glial cell pathology (axis B), and (3) the ratio of tau to $\alpha$-synuclein (axis C). Hence, these three variables are quantified and used as co-ordinates to plot each case within the triangle. In a $2 \mathrm{D}$ representation, these coordinates will provide three point locations for each individual case, i.e., based on axes $A / B$, axes $A / C$, and axes $B / C$. The centroid of the triangle formed by joining these three points can then be used to plot the final location of each case within the space.

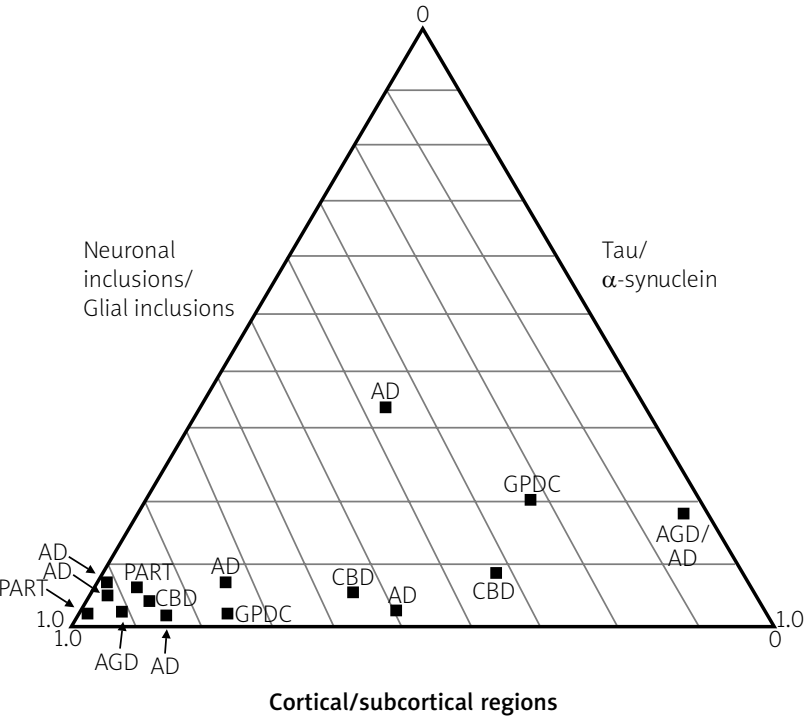

Fig. 6. Example of a triangular ordination applied to a mixed group of 15 tauopathy cases (AD - Alzheimer's disease, AGD - argyrophilic grain disease, CBD - corticobasal degeneration, PART - primary age-related tauopathy, GPDC - guamanian Parkinson dementia complex).

Figure 5 illustrates the most likely position of 'classic' cases of a number of tauopathies and synucleinopathies. Hence, cases with a predominantly AD-type pathology are located at or near the bottom left angle of the triangle (high neuronal/glia, cortical/ subcortical, and tau/ $\alpha$-synuclein ratios) whereas classic cases of multiple system atrophy (MSA) $[50,59]$ are located towards the top of the triangle to the right of the angle (low neuronal/glia, cortical/subcortical, and tau/ $\alpha$-synuclein ratios), overlap cases exhibiting multiple pathology would occupy intermediate positions. As an example, a miscellaneous group of 15 tauopathy cases, with various primary diagnoses, were quantified as described above and plotted within the triangle (Fig. 6). All cases clustered towards the base of the triangle, as expected, a region of high tau/ $\alpha$-synuclein ratios. However, there was considerable variation in location relative to axes A and B with little clustering of cases diagnosed as $A D$ or $C B D$, although the two cases diagnosed as primary age-related tauopathy (PART) $[26,30]$ did occur in relative proximity. Such a method could also be used to display cases in the interface between $A D$ and VD or different molecular subtypes of FTLD, e.g., with axes representing a tau or TDP-43-immunoreactive pathology. 


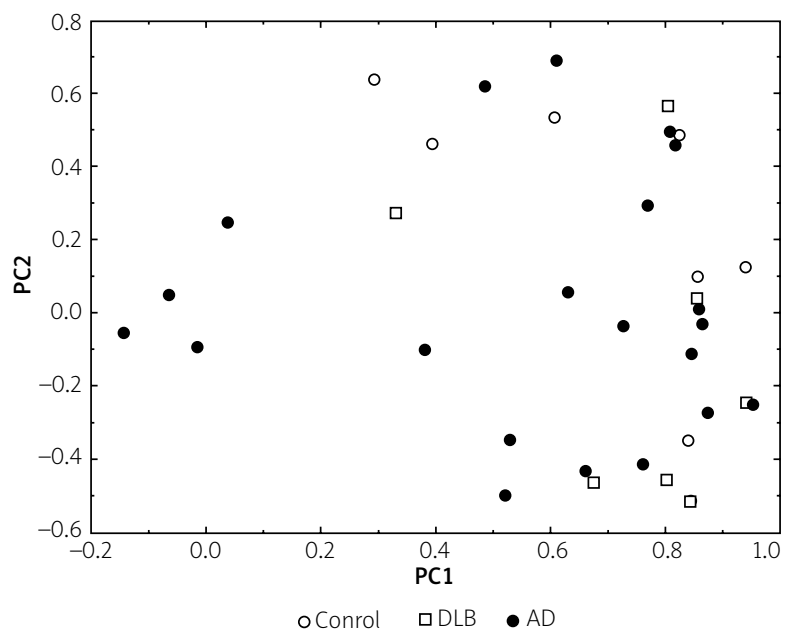

Fig. 7. Principal components analysis (PCA) of $\beta$-amyloid $(A \beta)$ deposition in the temporal lobe in control cases, dementia with Lewy bodies (DLB), and Alzheimer's disease (AD). A plot of the cases in relation to PC1 and PC2 (data from [8]). No distinct clusters of cases are present and there is extensive overlap among groups.

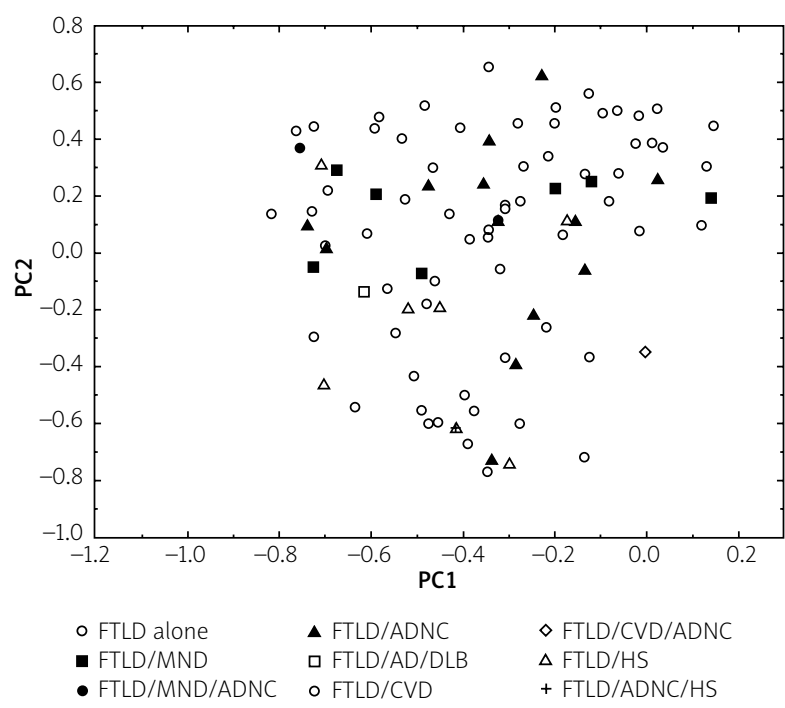

Fig. 8. Principal components analysis (PCA) of 94 frontotemporal lobar degeneration with TDP proteinopathy (FTLD-TDP) cases with various co-pathologies (ADNC - Alzheimer's disease neuropathologic change, DLB - dementia with Lewy bodies, HS - hippocampal sclerosis, MND - motor neuron disease, CVD - cerebro-vascular disease) (data from [17]). Cases as a whole form a continuum but with some clustering, e.g. those with MND as co-pathology while cases with $A D$ are more scattered.
A limitation of the triangular method is that three axes are likely to be insufficient to include all the variables needed to completely describe the neuropathology of a case. Hence, although a triangular-type system may be useful to describe cases from a restricted number of molecular groups, it is difficult to apply to all molecular pathologies that could be present, e.g., to also include $\beta$-amyloid $(A \beta)$, prion protein (PrPsc), TDP-43, and 'fused in sarcoma' (FUS) pathologies [16]. In addition, any system based on multiple geometry will need to be flexible enough to accommodate new molecular pathologies as they are discovered [48].

\section{Systems based on multivariate geometry}

Given the large number of possible descriptive variables, a more inclusive method of analysis is required. One such method is principal components analysis (PCA) [12,17] which enables the degree of similarity between cases to be studied based on all of their defining features $[6,12]$. PCA has frequently been used as a 'feature reduction' method, i.e., to reduce a large number of descriptive variables to a smaller number of more important defining variables [42,80] and hence, in the validation of questionnaires [71]. PCA has also been used to study spontaneous fluctuations in resting brain activity and in functional connectivity [51].

The result of a PCA applied to cases as variables is a scatter plot of the different cases in relation to the extracted principal components (PC) in which the distance between pairs of cases reflects their similarity or dissimilarity. The output from such an analysis is a series of eigenvalues ('latent roots') which are proportional to the variation accounted for by each axis, the eigenvectors ('latent vectors') representing the loadings, i.e., the spatial co-ordinates of each case in relation to the PC. A number of PC are extracted from the data each accounting for a specific proportion of the total variance, PC1 for the greatest individual proportion of the variance and remaining PCs for diminishing amounts of the remaining variance. Normally, two or three PCs account for most of the variance within the data, the fourth and successive PCs accounting for small and diminishing amounts of the residual variation, unless considerable heterogeneity is present. Such a system would appear to have the requisite multivariate geometry 
to provide a framework to accommodate any case of neurodegenerative disease regardless of molecular complexity. An important consideration, however, is the descriptive variables used to define each case and how they should be measured. Recently, a system based on multiple neuropathological features was described that could be used to provide such a framework, viz., the anatomical pathways affected by the disease ('anatomy'), the cell populations affected ('cells'), the molecular pathology of 'signature' pathological lesions ('molecules'), and the morphological types of neurodegeneration ('morphology'), each of which can be subdivided into several further variables as required [9].

Two examples of the application of PCA are illustrated: (1) a comparison of $\beta$-amyloid $(A \beta)$ deposition in control patients, AD and DLB [8] and (2) to examine the occurrence of multiple pathologies in FTLD [17]. In the first example, the densities of the diffuse, primitive, and classic $A \beta$ deposits in regions of temporal lobe were used as variables to study cognitively normal subjects and cases of AD and DLB [8]. PCA was used to determine whether there were distinct differences in $A \beta$ pathology between these groups or whether the pathology was more continuously distributed. Three principal components (PC) were extracted from the data accounting for $56 \%$ of the total variance. A plot of the cases in relation to PC1 and PC2 (Fig. 7) did not result in distinct clusters but suggested considerable overlap in $A \beta$ deposition among cases. In addition, there were linear correlations between the densities of $A \beta$ deposits and the distribution of the cases along the PC in specific brain regions suggesting continuous variation from group to group. Hence, PC1 was interpreted as variation in the degree to which diffuse were converted into more mature $A \beta$ deposits, $P C 2$ with differences between FAD and $S A D$, and $P C 3$ with variation in the extent to which $A \beta$ pathology spreads to affect the hippocampus.

In the second example, 94 cases of FTLD-TDP with a variety of co-pathologies were studied quantitatively [17]. Hence, FTLD-TDP pathology can occur in association with motor neuron disease (MND) [79], hippocampal sclerosis (HS) [4], and with varying degrees of ADNC [17]. Each case was characterised by the density of $\mathrm{NCl}, \mathrm{NII}, \mathrm{DN}$, and GI in frontal and temporal lobes [17] and a PCA of these data illustrating the distribution of the various co-pathologies is shown in Figure 8. Of the 94 cases, 68\% had no co-pathology, $22 \%$ had a least one co-pathology, either MND, ADNC, HS, or CVD, and $4 \%$ had two co-pathologies. The PCA suggests that the cases with associated MND appeared to cluster relative to PC2, occurring between factor loadings of 0 and +0.4 and therefore may be a more homogeneous subtype of FTLD-TDP whereas cases associated with ADNC as a co-pathology were significantly less clustered and more widely distributed over the plot.

\section{Discussion and conclusions}

A variety of methods are available for the quantitative description and analysis of neurodegenerative disease and many studies often employ multiple procedures. Hence, PCA has been used for feature reduction and classificatory methods then employed to distinguish between $A D$, mild cognitive impairment $(\mathrm{MCl})$, and control cases [80]. By contrast, a combination of HCA and discriminant analysis was used to distinguish among concentrations of various elements in the substantia nigra of Parkinson's disease (PD) and controls using X-ray fluorescent microscopy [23]. Various methods of classifying MRI data have been compared including O-PLS, DTA, ANN, and SVM, slightly better results being achieved using SVM and O-PLS $[2,65]$. PCA and HCA have been used to delineate different phenotypes within bvFTD which were shown to be associated with distinct anatomical patterns of neurodegeneration [65] while a combination of pre-processing, feature reduction, and classificatory methods has been demonstrated to provide the most efficient classificatory solutions [42]. Nevertheless, many of these applications often assume that discrete groupings do exist and the analyses are often used to support this assumption whereas in reality, the distribution of cases may be considerably more complex [8].

An important factor determining the relative utility of different quantitative methods, is the nature of neurodegenerative disease itself, i.e. whether it comprises distinct diseases, overlapping phenotypes, or a continuum [8]. If distinct disorders exist, then classificatory methods, such as cluster analysis or DTA, may be useful in establishing the actual groupings of cases more objectively. It is questionable, however, whether classificatory methods alone can adequately describe neurodegenerative disease as a whole given the degree of phenotypic heterogeneity [12,17], overlap between closely-related disorders [14], and 
the degree of multiple pathology commonly present [46]. Nevertheless, the presence of intermediate or overlap cases is recognised by the Braun-Blanquet system [20] and in constellation diagrams [1], both of which could be used to investigate the relationships between two or more closely related disorders such as AD and DLB or CBD and PSP. By contrast, multivariate geometry may be a more suitable method in situations where variation among cases is likely to be more continuously distributed. A triangular system may be useful in more restricted circumstances but a method such as PCA, which initially takes all descriptive variables into account and then reduces them to a smaller number of 'principal components', may be the most useful $[12,17]$. Several types of multivariate methods have been described [63] but their relative merits and limitations have yet to be studied with reference to neurodegenerative disease. Whichever methods ultimately emerge as the most useful, a major problem is the current lack of quantitative data of sufficient scope, quality, and consistency across categories of variables and disorders to define the individual cases appropriately [9].

Replacing any system of classification with a description based on overlapping phenotypes or a continuum may have several advantages. First, it may provide a more realistic description of neurodegenerative disease as a whole by emphasising its continuous nature and by incorporating disease heterogeneity and overlap to their true extent. In addition, it would not be necessary to assign new cases to a classification but instead they would be located within an existing continuum of cases [9]. Second, it would emphasise that common pathological mechanisms may be involved within larger groups of cases thus increasing the chance that a single 'unifying' theory could be proposed which could account for all phenotypic variants of disease [41]. Third, potentially new treatments could be assessed over larger numbers of cases rather than being exclusively tested on cases from a specific group or previously defined disease entity [34].

There are also potential disadvantages of a system based on multivariate geometry. These include a 'disconnect' with the traditional 'classic' disorders such as AD, DLB, and CJD, named entities which have existed for more than a century, and which could disappear as a result [75]. In addition, if distinct diseases are no longer recognised, there are implications for research studies which traditionally compare dis- ease and control groups, e.g., studies of disease risk factors, the pathogenesis of disease, and in clinical trials. Nevertheless, it would be possible to carry out these types of study using a 'continuum approach'. One method would be to replace the traditional comparison of disease and control groups with a trend analysis' in which the relationship between a quantitative measure, e.g., of a risk factor, pathogenic factor, or result of a clinical trial is tested against the location of the cases relative to a PC using polynomial curve fitting. For example, a PCA could be carried out on cases representing varying degrees of clinical dementia and possible risk factors identified by plotting the regression of each measure of risk against the 'loadings' of cases on the PC, a significant regression line indicating a possible risk factor. In a clinical setting, such an outcome might also demonstrate the extent to which a new treatment might be effective over a wide range of cases.

In conclusion, different methods of quantitative analysis each have a specific purpose, the basis of a classification being to provide defined units of disease based on clinico-pathological features so that new cases can be diagnosed and assigned to the various groupings readily. By contrast, multivariate geometry does not aim to classify cases but to describe the relationships among them and to display essentially continuous variation in disease phenotypes. The most important factor in ultimately deciding which type of the quantitative method is most effective is whether neurodegenerative disease can be regarded as comprising distinct disorders, overlapping phenotypes, or a 'continuum' of clinical and pathological change [8]. In the absence of a consensus on this question it is likely that combinations of different quantitative methods will continue to be applied to the analysis of neurodegenerative disease.

\section{Disclosure}

The author reports no conflict of interest.

\section{References}

1. Agnew ADQ. The ecology of Juncus effusus in North Wales. J Ecol 1961; 49: 83-102.

2. Aguilar C, Westman E, Muehlboeck JS, Mecocci P, Vellas B, Tsolaki M, Kloszewska I, Soininen H, Lovestone S, Spenger C, Simmons A, Wahlund LO. Different multivariate techinques for automated classification of MRI data in Alzheimer's disease and mild cognitive impairment. Psychiatry Res 2013; 212: 89-98. 
3. Alzheimer A. Über eine eigenartige Erkrankung der Hirnrinde. Allge Zeitsch Psychiatr und Psychisch-Gerich Med 1907; 64: 146-148.

4. Amador-Ortiz C, Lin WL, Ahmed Z, Personett D, Davies P, Dara R, Graff-Radford NR, Hutton ML, Dickson DW. TDP-43 immunoreactivity in hippocampal sclerosis and Alzheimer's disease. Ann Neurol 2007; 61: 435-445.

5. Andin U, Gustafson L, Passant U, Brun A. A clinic-pathological study of heart and brain lesions in vascular dementia. Dement Geriatr Cogn 2005; 19: 222-228.

6. Armstrong RA. Quantifying the pathology of neurodegenerative disorders: quantitative measurements, sampling strategies and data analysis. Histopathology 2003; 42: 521-529.

7. Armstrong RA. The interface between Alzheimer's disease, normal aging and related disorders. Curr Aging Sci 2008; 1: 122132.

8. Armstrong RA. On the 'classification' of neurodegenerative disorders: discrete entities, overlap, or continuum? Folia Neuropathol 2012; 50: 201-208.

9. Armstrong RA. Can neurodegenerative disease be defined by four 'primary determinants': anatomy, cells, molecules, and morphology? Folia Neuropathol 2016; 54: 89-104.

10. Armstrong RA, Wood L. The identification of pathological subtypes of Alzheimer's disease using cluster analysis. Acta Neuropathol 1994; 88: 60-66.

11. Armstrong RA, Cairns NJ, Lantos PL. The spatial patterns of Lewy bodies, senile plaques and neurofibrillary tangles in Dementia with Lewy bodies. Exp Neurol 1998; 150: 122-127.

12. Armstrong RA, Nochlin D, Bird TD. Neuropathological heterogeneity in Alzheimer's disease: A study of 80 cases using principal components analysis. Neuropathology 2000; 20: 31-37.

13. Armstrong RA, Cairns NJ, Lanto PL. A quantitative study of the pathological lesions in the neocortex and hippocampus of 12 patients with corticobasal degeneration. Exp Neurol 2000; 163: 348-356.

14. Armstrong RA, Cairns NJ, Lantos PL. Overlap between neurodegenerative disorders. Neuropathology 2005; 25: 111-124.

15. Armstrong RA, Lantos PL, Cairns NJ. Progressive supranuclear palsy (PSP): a quantitative study of the pathological changes in cortical and subcortical areas of eight cases. J Neural Transm 2007; 114: 1569-1577.

16. Armstrong RA, Lantos PL, Cairns NJ. What determines the molecular composition of abnormal protein aggregates in neurodegenerative disease? Neuropathology 2008; 28: 351-365.

17. Armstrong RA, Ellis W, Hamilton RL, Mackenzie IRA, Hedreen J, Gearing M, Montine T, Vonsattel J-P, Head E, Lieberman AP, Cairns NJ. Neuropathological heterogeneity in frontotemporal lobar degeneration with TDP-43 proteinopathy: a quantitative study of 94 cases using principal components analysis. J Neural Transm 2010; 117: 227-239.

18. Arnold SE, Toledo JB, Appleby DH, Xie SX, Wang LS, Baek Y, Wolk DA, Lee EB, Miller BL, Lee VMY, Trojanowski JQ. Comparative survey of the topographical distribution of signature molecular lesions in major neurodegenerative disease. J Comp Neurol 2013; 521: 4339-4353.

19. Bombois S, Duhamel A, Salleron J, Deramecourt V, Mackowiak MA, Deken V, Sergeant N, Pasquier F, Buee L, Sabionniere B,
Schraen-Maschke S. A new decision tree combing Abeta 1-42, and p-tau levels in Alzheimer's diagnosis. Curr Alz Res 2013; 10: 357 364.

20. Braun-Blanquet J. Pfanzensoziologie. $2^{\text {nd }}$ ed. Springer, Vienna, 1951.

21. Breiman L, Friedman JH, Olshen R, Stone C. Classification and regression trees. Wadsworth and Brooks, Pacific Grove 1984.

22. Cairns NJ, Bigio EH, Mackenzie IRA, Neumann M, Lee VMY, Hatanpaa KJ, White CL, Schneider JA, Grinberg LT, Halliday G, Duyckaerts C, Lowe JS, Holm IE, Tolnay M, Okamoto K, Yokoo H, Murayama S, Woulfe J, Munoz DG, Dickson DW, Ince PG, Trojanowski JQ, Mann DMA. Neuropathologic diagnostic and nosological criteria for frontotemporal lobar degeneration: consensus of the Consortium for Frontotemporal Lobar Degeneration. Acta Neuropathol 2007; 114: 5-22.

23. Chwiej J. The use of cluster and discriminant analysis in the investigations of the role of trace metals in the pathogenesis of Parkinson's disease. J Trace Elem Med Bio 2010; 24: 78-88.

24. Clifford HT, Sokal R. An Introduction to Numerical Classification. Academic Press, New York 1975.

25. Cortes C, Vapnik V. Support-vector networks. Mach Learn 1995; 20: 273-297.

26. Crary JF, Trojanowski JQ, Schneider JA, Abisambra JF, Abner EL, Alafuzoff I, Arnold SE, Attems J, Beach TG, Bigio EH, Cairns NJ, Dickson DW, Gearing M, Grinberg LT, Hof PR, Hyman BT, Jellinger K, Jicha GA, Kovacs GG, Knopman PS, Kofler J, Kukull WA, McKenzie IR, Masliah E, McKee A, Montine TJ, Murray ME, Neltner JH, Santa Maria I, Seeley WW, Serrano-Pozo A, Shelanski ML, Stein T, Takao M, Thal DR, Toledo JB, Troncoso J, Vonsattel JP, White CL, Wisniewski T, Woltjer RL, Yamada M, Nelson PT. Primary age-related tauopathy (PART): a common pathology associated with human aging. Acta Neuropathol 2014; 128: 755-766.

27. Creutzfeldt HG. Über eines eigenartige herd-formige Erkrankung des Zentralnervensystems. In: NissI F, Alzheimer A (eds.). Histologische und Histopathologische Arbeiten über die Grosshirnrinde. Gustav Fisher, Jena 1921; 1-48.

28. De Vries DM. Objective combinations of species. Acta Bot Neerl 1953; 1: 497-499.

29. Dickson DW, Ruan D, Crystal H, Mark MH, Davies P, Kress Y, Yen SH. Hippocampal degeneration differentiates diffuse Lewy body disease (DLBD) from Alzheimer's disease: Light and electron microscope immunocytochemistry of CA2-3 neurites specific to DLBD. Neurology 1991; 41: 1402-1409.

30. Dickson DW. Neuropathology of non-Alzheimer degenerative disorders. Int J Clin Exp Path 2009; 3: 1-23

31. Drouet B, Pincon-Raymond M, Chambaz J, Pillot T. Molecular basis of Alzheimer's disease. Cell Mol Life Sci 2000; 57: 705-715.

32. Feany MB, Dickson DW. Neurodegenerative disorders with extensive tau pathology: a comparative study and review. Ann Neurol 1996; 40: 139-148.

33. Fernando MS, Ince PG. Vascular pathologies and cognition in a population-based cohort of elderly people. J Neurol Sci 2004; 226: 13-17.

34. Forman MS, Trojanowski JQ, Lee VMY. Neurodegenerative diseases: a decade of discoveries paves the way for therapeutic breakthroughs. Nat Med 2004; 10: 1055-1063. 
35. Forstl H. Alzheimer's disease: the size of the problem, clinical manifestation and heterogeneity. J Neural Transm 1998; 54: 1-8.

36. Forstl $H$. The Lewy body variant of Alzheimer's disease: clinical, pathophysiological and conceptual issues. Eur Arch Psych Clin Neurol 1999; 249: 64-67.

37. Goodall DW. Objective methods for the classification of vegetation. I. The use of positive interspecific correlation. Aust J Bot 1953; 1: 39-63.

38. Grime JP. Plant Strategies and Vegetation Processes. John Wiley \& Sons, London 1979.

39. Gutierrez SLM, Rivero MH, Ramirez NC, Hernandez E, ArandaAbreu GE. Decision trees for the analysis of genes involved in Alzheimer's disease pathology. J Theor Biol 2014; 357: 21-25.

40. Hainfellner JA, Wanschitz J, Jellinger K, Liberski PP, Gullotta F, Budka $\mathrm{H}$. Coexistence of Alzheimer type neuropathology in Creutzfeldt-Jakob disease. Acta Neuropathol 1998; 96: 116-122.

41. Hardy J, Gwinn-Hardy K. Genetic classification of primary neurodegenerative disease. Science 1998; 282: 1075-1079.

42. Hariharan M, Polat K, Sindhu R. A new hybrid intelligent system for accurate detection of Parkinson's disease. Comp Meth Prog Biomed 2014; 113: 904-913.

43. Harrington CR, Perry RH, Perry EK, Hurt J, McKeith JG, Roth M Wischik CM. Senile dementia of the Lewy body type and Alzheimer type are biochemically distinct in terms of paired helical filaments and hyperphosphorylated tau proteins. Dementia 1994, 5: 215-228.

44. Hyman BT, Phelps CH, Beach TG, Bigio EH, Cairns NJ, Carrillo MC, Dickson DW, Duyckaerts C, Frosch MP, Masliah E, Mirra SS, Nelson PT, Schneider JA, Thal DR, Thies B, Trojanowski JQ Vinters HV, Montine TJ. National Institute on Aging-Alzheimer's Association guidelines for the neuropathologic assessment of Alz heimer's disease. Alzheimers Dement 2012; 8: 1-13.

45. Jakob A. Über eigenartige Erkrankungen des Zentralnervensys tems mit bemerkenswerten anatomischen Befunden (spas tische Pseudosklerose-Encephalomyelopathic mit disseminierten Degenerationsherden). Dtsch Z Nervenheilk 1921; 70: 132-146.

46. Jellinger KA, Attems J. Challenges of multimorbidity of the aging brain: a critical update. J Neural Transm 2015; 122: 505-521.

47. Josephs KA. Frontotemporal dementia and related disorders: Deciphering the enigma. Ann Neurol 2008; 64: 4-14.

48. Josephs KA, Holton JL, Rossor MN, Braendgaard H, Ozawa T, Fox NC, Petersen RC, Pearl GS, Ganguly M, Rosa P, Laursen $\mathrm{H}$, Parisi JE, Waldemar G, Quinn NP, Dickson DW, Revesz T. Neurofilament inclusion body disease: a new proteinopathy? Brain 2003 126: 2291-2303

49. Kumar A, Singh TR. A new decision tree to solve the puzzle of Alz heimer's disease pathogenesis through standard diagnosis scoring system. Interdiscip Sci 2017; 9: 107-115.

50. Lantos PL, Papp MI. Cellular pathology of multiple system atrophy: a review. J Neurol Neurosur Psychiatry 1994; 57: 129-113.

51. Leonardi N, Richiardi J, Gschwind M, Simioni S, Annoni JM, Schluep M, Vulleumier P, Van De Ville D. Principal components of functional connectivity: A new approach to study dynamic brain connectivity during rest. Neuroimage 2013; 83: 937-950.

52. Lewy FH. 'Paralysis agitans'. I. Pathologische Anatomie. In: Hand buch der Neurologie. Lewandowsky M (ed.). Julius Springer, Berlin 1912; 920-933.
53. Lim A, Tsuang D, Kukull D, Nochlin D, Leverenz J, McCormick W, Bowen J, Teri L, Thompson J, Peskind ER, Raskind M, Larsen EB. Clinico-neuropatholgoical correlation of Alzheimer's disease in a community-based case series. J Am Geriatr Soc 1999; 47: 564-569.

54. Litvan I, Agid Y, Calne D, Campbell G, Dubois B, Davoisin RC, Goetz CG, Golbe LI, Grafman J, Growden JH, Hallett M, Jankovic J, Quinn NP, Tolisa E, Zee DS, Chase TN, FitzGibbon EJ, Hall Z, Juncos J, Nelson KB, Oliver E, Pramstaller P, Reich SG, Verny M. Clinical research criteria for the diagnosis of progressive supranuclear palsy (Steele-Richardson-Olszewski syndrome): report of the NINDS-SPSP International Workshop. Neurology 1996; 47: 1-9.

55. Mackenzie IRA, Neumann M, Baborie, Sampathu DM, Du Plessis D, Jaros E, Perry RH, Trojanoswki JQ, Mann DMA, Lee VMY. A harmonized classification system for FTLD-TDP pathology. Acta Neuropathol 2011; 122: 111-113

56. Mariu W, Iseki E, Kosaka K, Kato M, Adachi Y, Ueda K. An autopsied case of Down's syndrome with Alzheimer pathology and alphasynuclein immunoreactivity. Neuropathology 1999; 19: 410-416.

57. McKeith IG, Galasko D, Kosaka K, Perry EK, Dickson DW, Hansen LA, Salmon DP, Lowe J, Mirra SS, Byrne EJ, Lennox G, Quinn NP, Edwardson JA, Ince PG, Bergeron C, Burns A, Miller BL, Lovestone S, Collerton D, Jansen ENH, Ballard C, de Vos RAI, Wilcock GK, Jellinger KA, Perry RH. Consensus guidelines for the clinical and pathological diagnosis of dementia with Lewy bodies (DLB): Report of the consortium on DLB international workshop. Neurology 1996; 47: 1113-1124.

58. Morris JC. The nosology of dementia. Neurol Clin 2000; 18: 773788.

59. Papp MI, Kahn JE, Lantos PL Glial cytoplasmic inclusions in the CNS of patients with multiple system atrophy (striatonigral degeneration, olivopontocerebellar atrophy, and Shy-Drager syndrome). J Neurol Sci 1989; 94: 79-100.

60. Perl DP, Olanow CW, Calne D. Alzheimer's disease and Parkinson's disease: distinct entities or extremes of a spectrum of neurodegeneration? Ann Neurol 1998; 44: S19-S31.

61. Petrovitch H, Ross GW, Steinhorn SC, Abbott RD, Markesbury W, Davis D, Nelson J, Hardman J, Masaki KH, Vogt MR, Launer LJ, White LR. AD lesions and infarcts in demented and non-demented Japanese-American men. Ann Neurol 2005; 57: 98-103.

62. Pick A. Über einen weiteren Symptomenkomplex im Rahman der Dementia senilis, bedingt durch umschriebene starkere Hirnatrophie (gemischte Apraxie). Monat Psych Neurol 1906; 19: 97-108.

63. Pielou EC. An introduction to Mathematical Ecology. John Wiley, New York, London, Sydney and Toronto 1969.

64. Quinlan JR. Simplifying decision trees. Int J Man-Machine Studies 1987; 27: 221-234.

65. Ranasinghe KG, Rankin KP, Pressman PS, Perry DC, Lobach IV, Seeley WW, Coppola G, Karydas AM, Grinberg LT, Shany-Ur T, Lee SE, Rabinovici GD, Rosen HJ, Gorno-Tempini ML, Boxer AL, Miller ZA, Chiong W, Demay M, Kramer JH, Poisson KL, Sturm VE, Bettcher BM, Neylan M, Zackey DD, Nguyen LA, Ketelle R, Block N, Wu TQ, Dallich A, Russek N, Caplan A, Geschwind DH, Vossel KA, Miller BL. Distinct subtypes of behavioural variant frontotemporal dementia based on patterns of network degeneration. JAMA Neurol 2016; 73: 1078-1088.

66. Russell SJ, Norvig P. Artificial intelligence: A modern approach. Prentice Hall, 2010. 
67. Sadeghi N, Foster NL, Wang AY, Minoshima S, Lieberman AP, Tasdizen T. Automatic classification of Alzheimer's disease vs. frontotemporal dementia: A spatial decision tree approach with FDGPET. IEEE Inter Symp Biomed Imag 2008; 1-4: 408-411.

68. Sampathu DM, Neumann M, Kwong LK, Chou TT, Micsenyi M, Truax A, Bruce J, Grossman M, Trojanowski JQ, Lee VMY. Pathological heterogeneity of frontotemporal lobar degeneration with ubiquitin-positive inclusions delineated by ubiquitin immunohistochemistry and novel monoclonal antibodies. Am J Pathol 2006; 189: 1343-1352.

69. Schneider JA, Arvanitakis Z, Bang W, Bennett DA. Mixed brain pathologies account for most dementia cases in community-dwelling older persons. Neurology 2007; 69: 2197-2204.

70. Schneider JA, Boyle PA, Arvanitakis Z, Bienias JL, Bennett DA. Subcortical infarcts, Alzheimer's disease pathology, and memory function in older persons. Ann Neurol 2007; 62: 59-66.

71. Scullin MK, Harrison TL, Factor SA, Bliwise DL A neurodegenerative disease sleep questionnaire: Principal component analysis in Parkinson's disease. J Neurol Sci 2014; 336: 243-246.

72. Sokal RR, Sneath HA. Principles of numerical taxonomy. WH Freeman, San Francisco 1963.

73. Tian C, Liu D, Xiang W, Kretzschmar HA, Sun QL, Gao C, XU Y, Wang H, Fan XY, Meng G, Li W, Dong XP. Analysis of the similarity and difference of global gene expression profiles in cortex regions of three neurodegenerative diseases: sporadic Creutzfeldt-Jakob disease, fatal familial insomnia (FFI), and Alzheimer's disease (AD). Mol Neurobiol 2014; 50: 473-481.

74. Trygg J, Wold S. Orthogonal projections to latent structures (O-PLS). J Chemometr 2002; 16: 119-128.

75. Wallin A, Blennow K. Clinical subgroups of Alzheimer's syndrome. Acta Neurol Scand 1996; 93: 51-57.

76. Wicklund MR, Duffy JR, Strand EA, Machulda MM, Whitwell JL, Josephs KA. Quantitative application of the primary progressive aphasia consensus criteria. Neurology 2014; 82: 1119-1126.

77. Whitwell JL, Jack CR, Senjem ML, Josephs KA. Patterns of atrophy in pathologically confirmed FTLD with or without motor neuron degeneration. Neurology 2006; 66: 102-104.

78. Whitwell JL, Przybelski SA, Weigand SD, Ivnik RJ, Vemuri P, Gunter JL, Senjem ML, Shiung MM, Boeve BF, Knopman DS, Parisi JE, Dickson DW, Petersen RC, Jack CR, Josephs KA. Distinct anatomical subtypes of the behavioural variant of frontotemporal dementia: a cluster analysis study. Brain 2009; 132: 2932-2946.

79. Yokoyama JS, Bonham LW, Sears RL, Klein E, Karydas A, Kramer JH, Miller BL, Coppola G. Decision tree analysis of genetic risk for clinically heterogeneous Alzheimer's disease. BMC Neurol 2015; 15: 47.

80. Zhang YD, Wang SH, Phillips P, Dong ZC, Ji GL, Yang JQ. Detection of Alzheimer's disease and mild cognitive impairment based on structural volumetric MR images using 3D-DWT and WTA-KSVM trained by PSOTVAC. Biomed Sig Proc Cont 2015; 21: 58-73. 